\title{
Interannual variability in phytoplankton blooms and plankton productivity over the Nova Scotian Shelf and in the Gulf of Maine
}

\author{
Hongjun Song ${ }^{1,2}$, Rubao $\mathrm{Ji}^{2,3, *}$, Charles Stock ${ }^{4}$, Kelly Kearney ${ }^{5}$, Zongling Wang ${ }^{1}$ \\ ${ }^{1}$ Key Lab of Science and Engineering for Marine Ecological Environment, The First Institute of Oceanography, SOA, \\ Qingdao 266061, PR China \\ ${ }^{2}$ Department of Biology, Woods Hole Oceanographic Institution, Woods Hole, Massachusetts 02543, USA \\ ${ }^{3}$ Marine Ecosystem and Environment Laboratory, College of Marine Sciences, Institutes for Marine Sciences, Shanghai \\ Ocean University, Shanghai 201306, PR China \\ ${ }^{4}$ NOAA Geophysical Fluid Dynamics Laboratory, Princeton University Forrestal Campus, Princeton, New Jersey 08540, USA \\ ${ }^{5}$ Department of Geosciences, Princeton University, Princeton, New Jersey 08540, USA
}

\begin{abstract}
A 1D ecosystem model, driven by surface heat and wind forcing and relaxed toward observed salinity profiles, was applied to simulate the interannual and decadal scale variability of phytoplankton blooms and plankton production from 1984 to 2007 in the Nova Scotian Shelf (NSS) and Gulf of Maine (GoM) region. The model captured the mean observed timing and magnitude of the spring (SPB) and fall phytoplankton bloom (FPB) in both systems, as well as observed interannual variations in SPB peak timing. Model simulations for both the GoM and NSS exhibited marked interannual variability in SPB and FPB timing ( \pm 2 to $3 \mathrm{wk}$ ) and magnitude (up to $\sim 1 \mathrm{mg}$ chlorophyll $\mathrm{m}^{-3}$ ). Earlier SPBs and delayed FPBs are linked to enhanced water column stability generated by less saline surface water or sharper salinity gradients over the top $50 \mathrm{~m}$ of the water column. The modeled variation in annual primary productivity, mesozooplankton productivity, and particle export flux was modest $(<10 \%$ of the mean). Years with high primary production were weakly associated with early SPBs (GoM: $r=-0.205$; NSS: $r=-0.51$ ), but there was no significant relationship with water column stability. This suggests that variation in annual productivity in the GoM and NSS reflects a combination of variation in light limitation (which is alleviated by increased water column stability) and nutrient limitation (which is exacerbated by increased water column stability) that offset and are of near equal importance when averaged over the year. Interannual variations in fisheries production due to changes in annual productivity are thus likely secondary to profound shifts in fisheries recruitment and production that have been linked to variations in SPB and FPB timing.
\end{abstract}

KEY WORDS: Phytoplankton bloom - Interannual variability · Modeling · Nova Scotian Shelf · Gulf of Maine

Resale or republication not permitted without written consent of the publisher

\section{INTRODUCTION}

Phytoplankton standing stocks in most temperate coastal ecosystems undergo strong seasonal cycles, and typically exhibit a major spring bloom in late winter/early spring and a lesser fall bloom. A balance between nutrient entrainment and light limitation, regulated by the depth of the mixed layer relative to the critical depth (Sverdrup 1953), has long been invoked to explain phytoplankton bloom dynamics. Conse- quently, the interannual variation of environmental factors associated with the mixed layer depth (MLD), such as temperature, salinity, wind, and nutrient concentrations, is likely to cause phenological shifts in phytoplankton blooms, alter annual primary production, and affect the flow of energy to higher trophic levels and the export of energy to the benthos.

The shelf region from the Nova Scotian Shelf (NSS) to the Gulf of Maine (GoM) is a dynamic and highly productive system (Sherman et al. 1996). Climate- 
related environmental change might have caused significant decadal shifts in the state of the pelagic ecosystems in the NSS-GoM region (e.g. Durbin et al. 2003, Frank et al. 2005, Greene \& Pershing 2007, Ji et al. 2007), presumably through a bottom-up process. Understanding phytoplankton bloom dynamics and its relationship with environmental factors has long been the focus of ecosystem studies in the Gulf of Maine and adjacent regions (e.g. Bigelow 1926, Bigelow et al. 1940, Cushing 1959, Townsend \& Spinard 1986, Thomas et al. 2003, Ji et al. 2006). In recent years, interannual variations of phytoplankton bloom dynamics have been better detected with the help of field surveys (e.g. Durbin et al. 2003) and advances in technology such as remote sensing (e.g. Thomas et al. 2003, Ji et al. 2007) and continuous plankton recorders (e.g. Sameoto 2001, Greene \& Pershing 2007). Most of these recent studies have focused on the spring phytoplankton bloom (SPB). There has been little analysis of the potential impacts of changes in bloom timing on the overall ecosystem productivity, and limited attention has been given to the fall phytoplankton bloom (FPB), although its importance has been increasingly recognized (Greene \& Pershing 2007, Friedland et al. 2008). Lastly, most previous studies of phytoplankton blooms in this region used either empirical data analysis approaches (e.g. Townsend \& Spinard 1986, Townsend et al. 1992, Thomas et al. 2003, Ji et al. 2007), process-oriented modeling with focus on episodic events (e.g. Ji et al. 2006), or scenario testing (e.g. Ji et al. 2008).

In this study, we applied a 1D ecosystem model and conducted multi-year (1984 to 2007) continuous model runs to examine the effect of environmental factors on the interannual variability of phytoplankton blooms and plankton productivity in the NSS-GoM region. We first assessed the skill of the 1D model in simulating water column properties (e.g. temperature, MLD, and nutrients) and phytoplankton blooms for the years with available satellite chlorophyll data (1998 to 2007), and then conducted a longer model run (1984 to 2007) to resolve decadal scale variability. In addition to SPB dynamics, we also examined the FPB dynamics, the relationship between the SPB and FPB, and interannual variations in productivity. The following specific questions are considered in this paper:

(1) What are the temporal and regional variations of the timing and magnitude of SPBs and FPBs in the NSS-GoM region from 1984 to 2007 ?

(2) What are the major factors controlling the temporal and regional variability of the timing and magnitude of SPBs and FPBs?

(3) What is the relationship between phytoplankton blooms and annual primary and mesozooplankton production, and what effect does bloom variability have on the energy flow from primary producers to mesozooplankton and from pelagic to benthic components?

\section{MATERIALS AND METHODS}

Study sites and data sources. Two sites in the GoM and NSS were selected for the 1D modeling study (Fig. 1), which allowed us to compare 2 systems with different hydrographic features and external forcing. Both sites are representative of deep-water regions, with an understanding that the 1D model is less capable of capturing near-shore dynamics, which usually show strong advection-induced variability. There are strong links between deep shelf waters and shallow waters (e.g. productive Georges Bank). For instance, Calanus finmarchicus populations in the deep basins of the GoM and NSS contribute significantly to the Georges Bank population (Miller et al. 1998). Therefore, the variability of bloom timing and primary productivity in the deep sites can be translated to changes in productivities at the lower and higher trophic levels in the shallow-water systems.

Surface heat flux and wind data were obtained from the National Centers for Environmental Prediction/ National Center for Atmospheric Research (NCEP/ NCAR) reanalysis data (Kalnay et al. 1996) and the International Satellite Cloud Climatology Project (ISCCP) surface radiative flux data (Zhang et al. 2004). Temperature and salinity profile data were obtained from the Canadian Ocean Science Hydrographic Climate Database (www.mar.dfo-mpo.gc.ca/) for the period 1984 to 2007, and simple MATLAB griddata routine (linear interpolation) was used to treat the

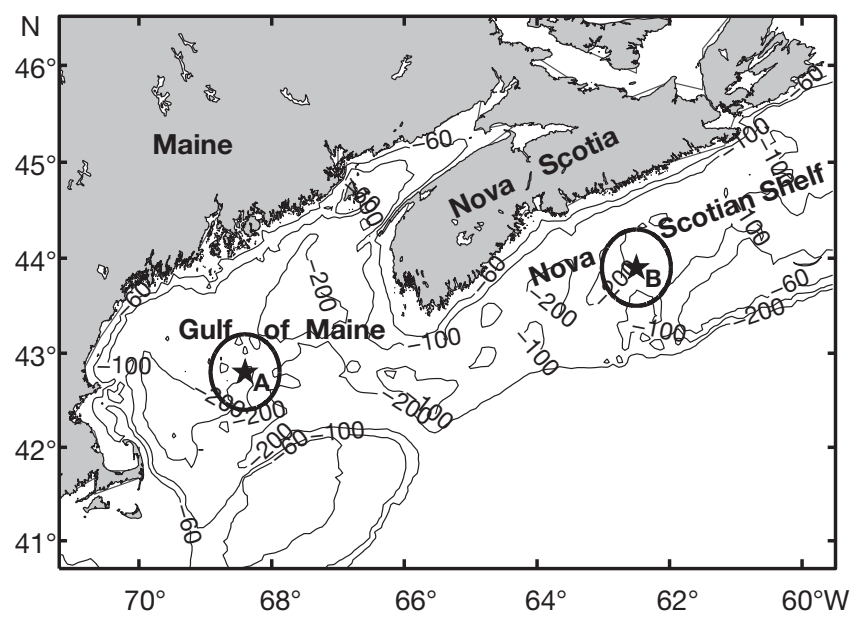

Fig. 1. Study region with 2 modeling sites (stars; A: Gulf of Maine site, B: Nova Scotian Shelf site) and surrounding zones for data analyses (circles, radius $=0.4^{\circ}$ ) 
salinity time series. A quadratic polynomial fit was used to smooth the salinity data below $50 \mathrm{~m}$ depth (where data were often sparse). Sea-viewing Wide Field-of-view Sensor (SeaWiFS) Level-3 mapped daily chlorophyll data with $9 \mathrm{~km}$ resolution were retrieved from the National Aeronautics and Space Administration (NASA) ocean-color website (http://seadas.gsfc. nasa.gov/) for the period 1998 to 2007.

Model description. A MATLAB-based 1D mixedlayer model was used to simulate the evolution of the physical water column properties between 1984 and 2007. The mixed layer is forced by observed winds, shortwave radiation, surface air and dew point temperatures, and a mean pressure gradient force. The pressure gradient force is imposed to create a mean current of the same order as what is observed for coastal currents in this region $\left(\sim 10\right.$ to $\left.20 \mathrm{~cm} \mathrm{~s}^{-1}\right)$. The salinity is relaxed to observations throughout the water column on a $5 \mathrm{~d}$ time scale, which allows salinity stratification to break down during storm events ( 2 to 3 d) but preserves the monthly to seasonal evolution of the salinity field. The primary results were insensitive to changes in this relaxation time-scale between 1 and $10 \mathrm{~d}$, and imposing longer relaxation time scales led to significant deep biases in the modeled MLDs (see Supplement 1 at www.int-res.com/articles/suppl/m426p105_ supp.pdf). Observed winds are translated to wind stresses using the bulk formulae of Large \& Pond (1981). The heat flux calculations follow those used by Mountain et al. (1996) in their study of surface heat fluxes in the Gulf of Maine. Latent and sensible heat fluxes are calculated from the wind speed, air-sea temperature difference, and the dew point temperature using bulk formulae of Friehe \& Schmitt (1976). Longwave radiation losses are calculated using the Efimova formula as reported by Simpson \& Paulson (1979). Of the incoming shortwave radiation, $45 \%$ is assumed to be photosynthetically available (Baker \& Frouin 1987) and is attenuated in the water column assuming a background attenuation of $0.1 \mathrm{~m}^{-1}$ and shading by chlorophyll (Lorenzen 1972). The grid spacing is $5 \mathrm{~m}$ and mixing is calculated with the Mellor-Yamada 2.5 algorithm with a background diffusivity of $1 \times 10^{-4} \mathrm{~m}^{2}$ $\mathrm{s}^{-1}$ (a relatively large but reasonable value to represent the impacts of strong tidal currents in this region, Lee et al. 2006). The water column depth is set to $100 \mathrm{~m}$ on the NSS and $150 \mathrm{~m}$ for the GoM.

The ecosystem model is an adaptation of the model of Stock \& Dunne (2010) to a 1D water column. The model structure is shown in Fig. 2. It was designed to resolve the primary energy flows within the planktonic food web and was used by Stock \& Dunne (2010) to analyze global patterns in primary production, mesozooplankton production, and export. The compartments represent a core set of functional groups with rudimen- tary size differentiation common in many ecosystem models. Nitrogen (N) is set to $14 \mathrm{mmol} \mathrm{N} \mathrm{m}^{-3}$ at the bottom boundary for the NSS and $20 \mathrm{mmol} \mathrm{N} \mathrm{m}^{-3}$ for the GoM. A Monod growth model is used for nutrientlimited growth. The light dependence is modeled according to Geider et al. (1997) and allows for variable chlorophyll-to-carbon ratios. Zooplankton have a Holling type 2 response for a single prey type and are assumed to engage in abundance-based switching when multiple prey types are available. The primary difference between small and large phytoplankton is an order of magnitude difference in half-saturation constants for nutrient uptake. The primary difference for the zooplankton types is a decline in the maximum grazing rate with increased size. Further details of the formulation of both the physical and biological models can be found in Supplement 2 at www.int-res.com/ articles/suppl/m426p105_supp.pdf.

Bloom timing and magnitude. To quantify the dynamics of SPB and FPB, we chose the peak timing and magnitude of the blooms as indices. First, SeaWiFS chlorophyll daily data were averaged in both areas (specified in Fig.1) after deleting outliers (departure from mean $>0.05$ significance). Then, the peak timing $\left(t_{\mathrm{m}}\right)$ was derived from a shifted-Gaussian model fit (e.g. Yamada \& Ishizaka 2006, Platt et al. 2009):

$$
\operatorname{Chl}(t)=\mathrm{B} 0+\text { Peak } \times \exp \left[-\frac{\left(t-t_{\mathrm{m}}\right)^{2}}{2 \sigma^{2}}\right]
$$

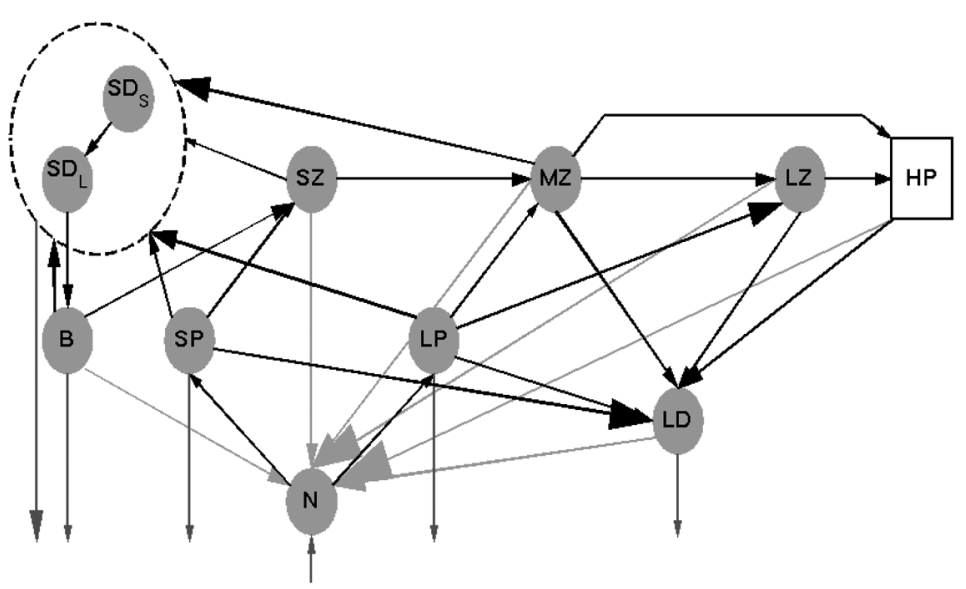

Fig. 2. Ecosystem model structure. There are 10 state variables (grey circles): $\mathrm{SP}=$ small phytoplankton, $\mathrm{LP}=$ large phytoplankton, $\mathrm{SZ}=$ small zooplankton, $\mathrm{MZ}=$ medium-sized zooplankton, $\mathrm{LZ}=$ large zooplankton, $\mathrm{B}=$ bacteria, $\mathrm{SD}_{\mathrm{L}}=$ labile small detritus, $\mathrm{SD}_{\mathrm{S}}=$ semi-labile small detritus, $\mathrm{LD}=$ large detritus, and $\mathrm{N}=$ limiting nutrient. $\mathrm{HP}=$ higher predators that are not explicitly resolved. Downward pointed darkgrey arrows that do not terminate at a state variable represent export from the euphotic zone via either sinking or mixing. Light grey arrows indicate recycling to the nutrient pool. All other arrows are shown in black. Dashed circle $=$ combined detrital pool. Details can be found in Stock \& Dunne (2010) 
where B0, Peak, $t_{\mathrm{m}}$, and $\sigma$ are the baseline concentration, peak concentration, peak timing, and standard deviation of the Gaussian curve, respectively. The average chlorophyll concentration over the bloom period was used as the bloom magnitude metric rather than the peak chlorophyll concentration estimated from Eq. (1), which was generally found to be an unreliable indicator of typical chlorophyll concentrations over the bloom. The SPB duration in the GoM and the NSS is usually from March to June and February to May, respectively, and the FPB is from September to December at both sites (Song et al. 2010). We therefore defined the average chlorophyll concentration from 1 March to 30 June in the GoM (or 1 February to 31 May in the NSS) as the SPB magnitude, and the average from 1 September to 31 December as the FPB magnitude at the 2 sites.

Five different environmental factors were analyzed for their potential roles in controlling the peak bloom magnitude and timing: sea surface temperature (SST), sea surface salinity (SSS), 0-50 m salinity difference, mean wind speed, and winter nutrients in surface waters. For SPB cases, March/April conditions were considered, while for FPB cases, October/November conditions were considered.

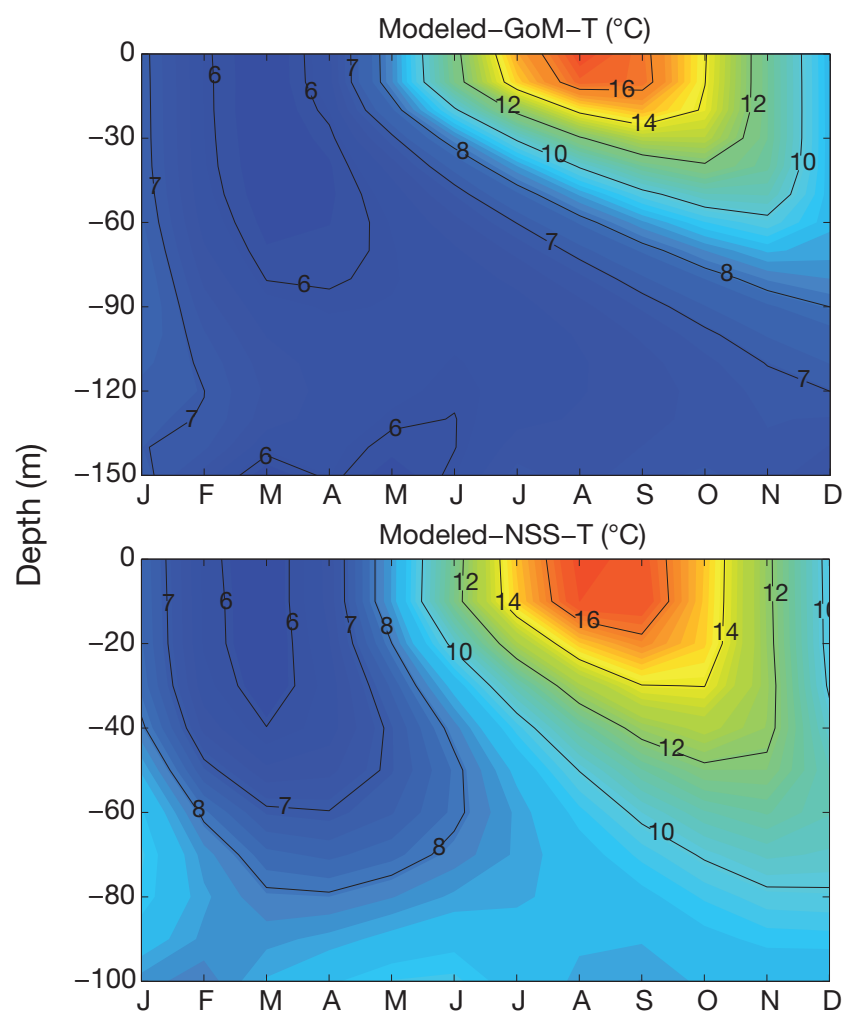

pe-ratio and $z$-ratio. To examine the relationship between bloom dynamics and production processes in the water column, we estimated both the pe-ratio and the $z$-ratio from the model output. The pe-ratio, or particle export ratio, is the ratio of the flux of organic particles out of the euphotic zone over the net primary production (NPP, defined as the difference between total photosynthesis and total phytoplankton respiration) within the euphotic layer. It provides a measure of the flow of energy to the benthos. The $z$-ratio is the ratio of mesozooplankton production to primary production (Stock \& Dunne 2010) and provides a measure of the energy available to the pelagic food web. These are calculated as:

$$
\begin{gathered}
\text { pe }- \text { ratio }=\frac{\text { Flux }_{\mathrm{SP}}+\text { Flux }_{\mathrm{LP}}+\text { Flux }_{\mathrm{LD}}}{\operatorname{Prod}_{\mathrm{SP}}+\operatorname{Prod}_{\mathrm{LP}}} \\
z \text { - ratio }=\frac{\operatorname{Prod}_{\mathrm{MZ}}+\operatorname{Prod}_{\mathrm{LZ}}}{\operatorname{Prod}_{\mathrm{SP}}+\operatorname{Prod}_{\mathrm{LP}}}
\end{gathered}
$$

where Flux $\mathrm{SP}_{\mathrm{SP}}$, Flux $_{\mathrm{LP}}$, and Flux $\mathrm{LD}_{\mathrm{L}}$ are respectively the sinking fluxes of small phytoplankton (SP, $<5 \mu \mathrm{m}$ in equivalent spherical diameter, ESD), large phytoplankton (LP, > $5 \mu \mathrm{m}$ ESD), and large detritus (LD) out of the top $50 \mathrm{~m}$. The sum of these 3 terms represents the total
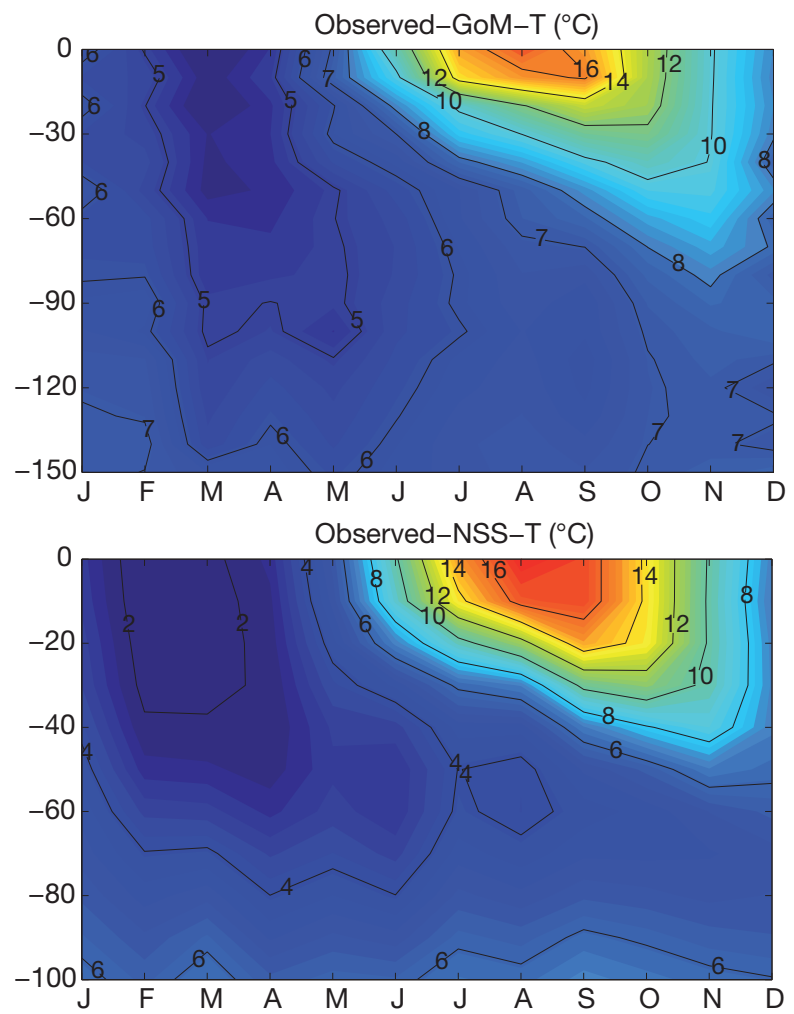

Fig. 3. Comparison of the observed and modeled climatological seasonal temperature cycle for the Gulf of Maine (GoM) and Nova Scotian Shelf (NSS). Observations were averaged over $10 \mathrm{~m}$ depth intervals and monthly time bins 
sinking flux of the particulate organic carbon (i.e. total particle export flux, PEF) at a depth of $50 \mathrm{~m}$. Prod SP $_{\text {, }}$ $\operatorname{Prod}_{\mathrm{LP}}, \operatorname{Prod}_{\mathrm{MZ}}$, and $\operatorname{Prod}_{\mathrm{LZ}}$ are the productions of SP, LP, medium-sized zooplankton (MZ, small to mediumbodied copepods between $\sim 200$ and $2000 \mu \mathrm{m}$ ESD), and large zooplankton (LZ, large copepods, euphausids, and predatory zooplankton between $\sim 2 \mathrm{~mm}$ and $2 \mathrm{~cm}$ ESD), respectively, within the top $50 \mathrm{~m}$ water column. 'Mesozooplankton production' in this study includes both MZ production and LZ production.

\section{RESULTS}

\section{Model skill assessment}

We first assessed the model skill in simulating the physical environment from 1984 to 2007. The prominent seasonal temperature cycles in both the GoM and the NSS are well captured in the model (Fig. 3), although there is some warm bias in both systems. This bias is likely due to the advection of cold water from the higher-latitude upstream region that is not captured by the 1D model (Umoh \& Thompson 1994, Mountain et al. 1996).

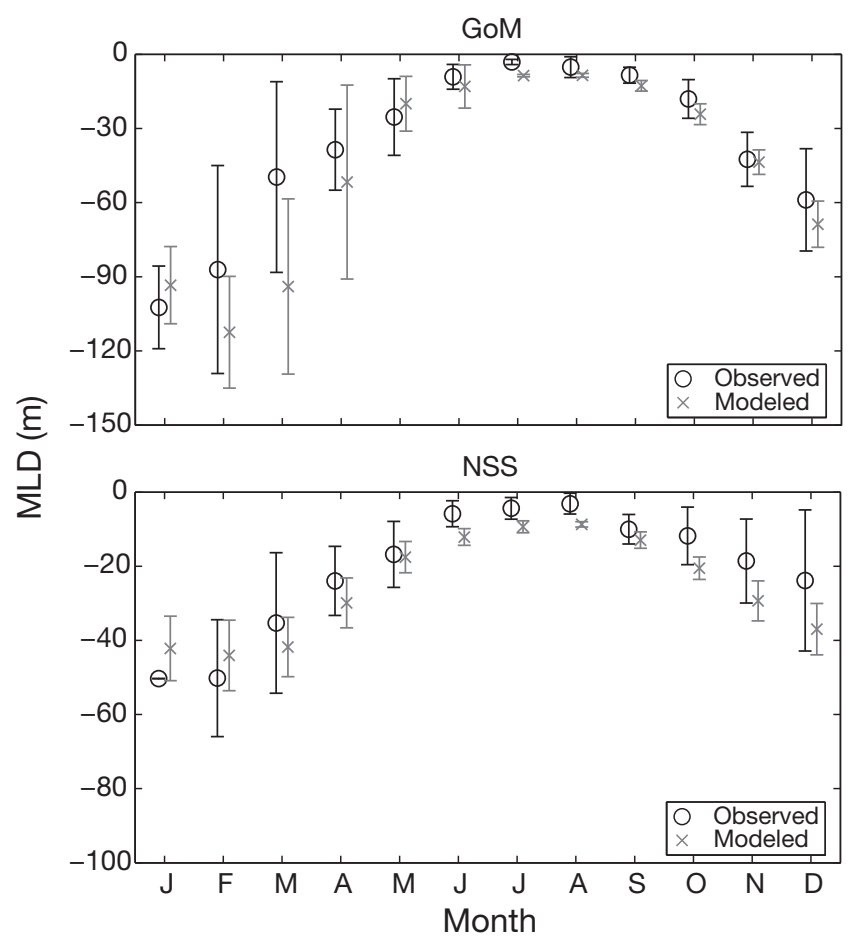

Fig. 4. Observed and modeled monthly mixed layer depth (MLD) cycle. MLDs were defined as the depth at which the density in the upper layer changed by $0.1 \mathrm{~kg} \mathrm{~m}^{-3}$ relative to the surface. Vertical bars: SD of the observed and modeled MLDs for the period of 1984 to 2007. GoM: Gulf of Maine; NSS: Nova Scotian Shelf
The model-computed MLD also agrees reasonably well with the observed MLD at the monthly cycle scale in both the GoM and NSS (Fig. 4). The correlation between the modeled and observed monthly mean MLD is 0.929 in the GoM and 0.932 on the NSS $(n=12)$. Deeper observed winter mixing in the GoM relative to the NSS is well captured by the model. In the GoM, the mean modeled MLD during March is deeper than typical observed values. However, both the modeled and observed MLDs during this period are highly variable, as observations are relatively scarce during the winter and early spring and the MLD is evolving quickly at this time. Closer agreement between model and data is regained quickly in April. The observed MLD appears to be slightly shallower than the modeled MLD during the summer months. The observed MLD during this period, however, is derived from a linear interpolation between surface and $10 \mathrm{~m}$ values. Observed MLD shallower than $10 \mathrm{~m}$ could thus lie anywhere between 0 and $10 \mathrm{~m}$.

The modeled drawdown of nutrients in the top $50 \mathrm{~m}$ matches what Petrie \& Yeats (2000) observed at both sites (Fig. 5), although the observed spike in nitrate in January on the NSS is not well captured by the model. Winter nitrate observations are sparse, but this peak could come from processes not resolved by the 1D model, such as upwelling near the coast or export of

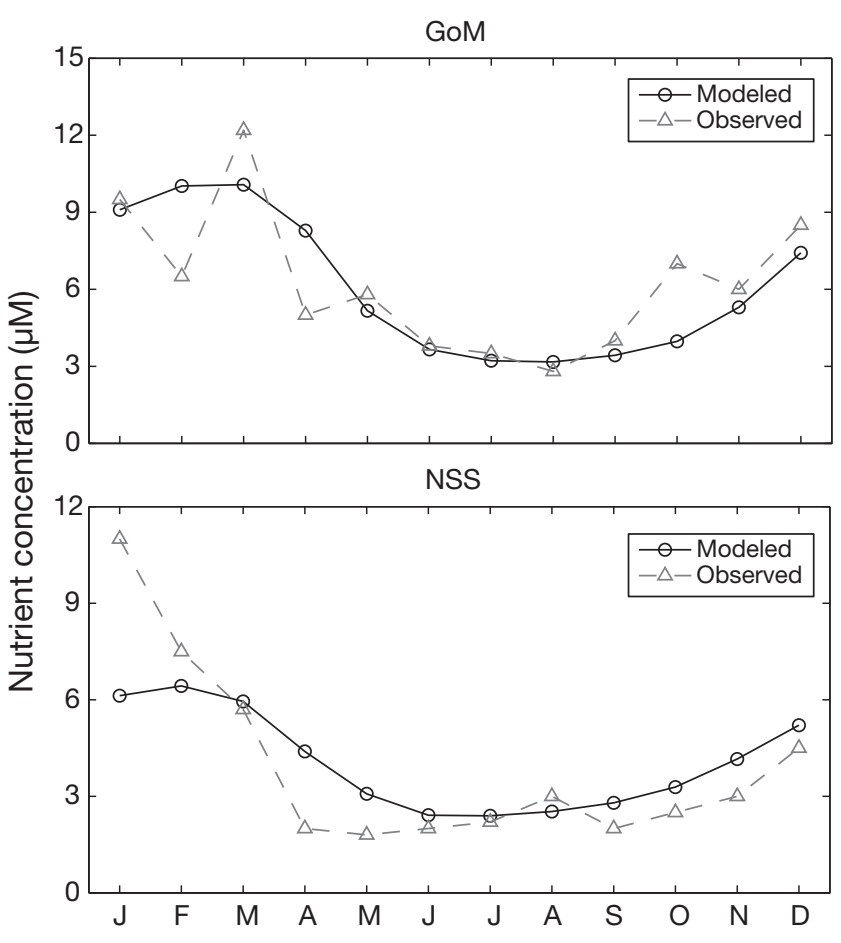

Fig. 5. Observed and modeled climatological-monthly 0 to $50 \mathrm{~m}$ average nutrient concentrations. The observed data are after the nitrate concentrations of Petrie \& Yeats (2000). GoM: Gulf of Maine; NSS: Nova Scotian Shelf 
nitrate from the Gulf of Saint Lawrence (Petrie \& Yeats 2000).

The model-computed daily surface chlorophyll concentrations were also compared to the SeaWiFS-derived
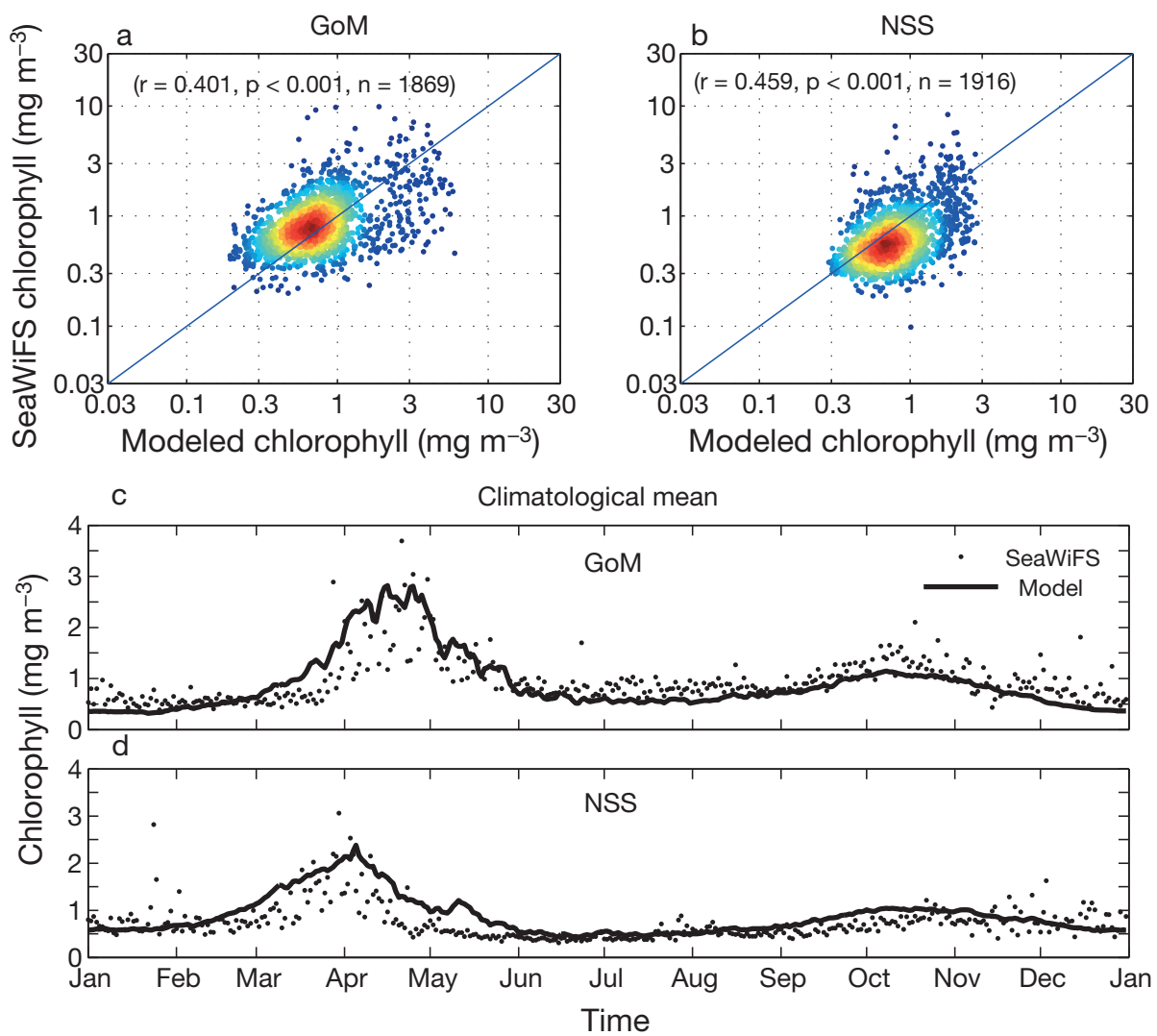

Fig. 6. Comparison of surface chlorophyll (daily) from SeaWiFS and the model for $(\mathrm{a}, \mathrm{c})$ the Gulf of Maine (GoM) and (b,d) the Nova Scotian Shelf (NSS). Colors in $(a, b)$ reflects the density of data points in the scatterplot: red areas have more data points than blue areas
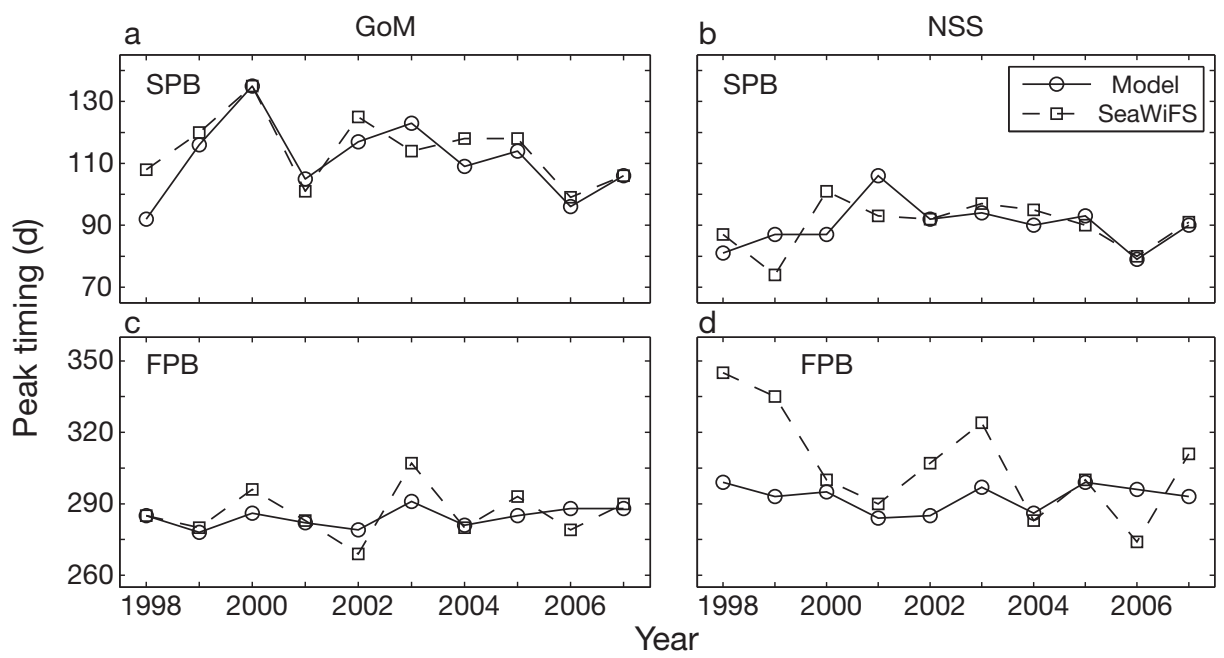

Fig. 7. Comparison of bloom peak timing from SeaWiFS and the model for $(a, c)$ the Gulf of Maine $(G o M)$ and $(b, d)$ the Nova Scotian Shelf (NSS). Spring/fall phytoplankton bloom (SPB/FPB) peak timing was fitted by the shifted-Gaussian model with data in the first/second half year 

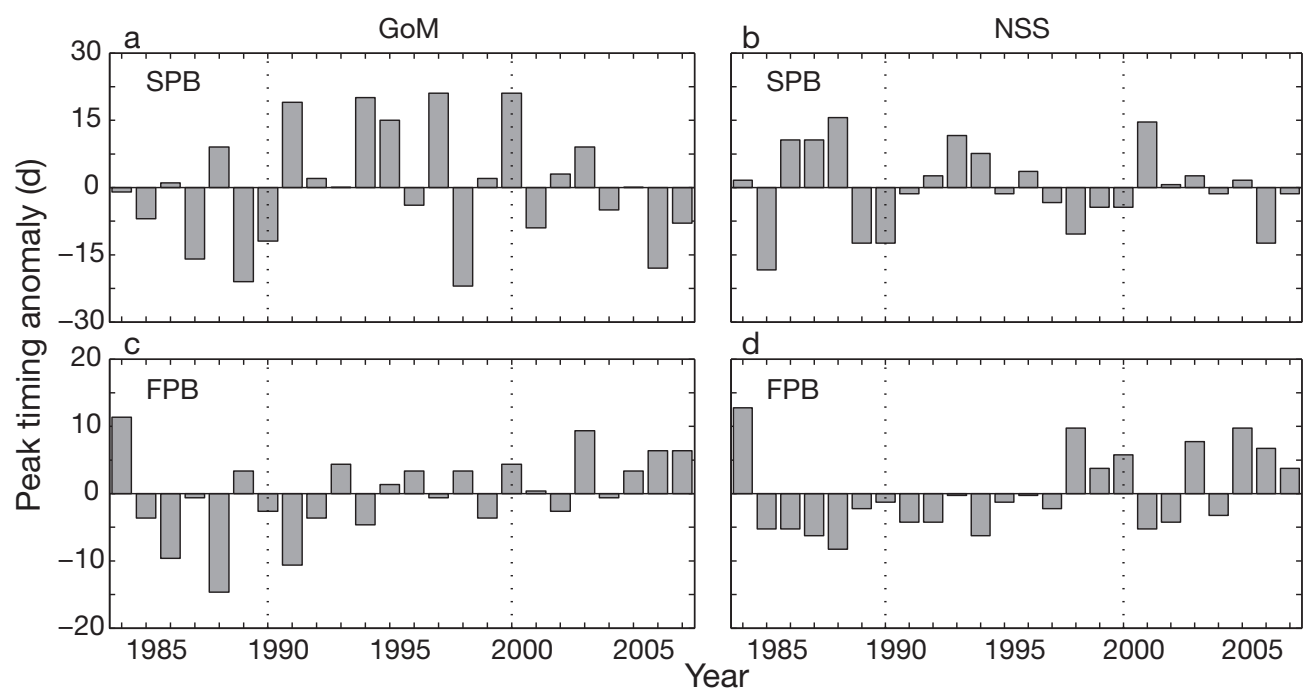

Fig. 8. Modeled interannual variability of bloom peak timing (mean day of year) in $(a, c)$ the Gulf of Maine (GoM) and $(b, d)$ the Nova Scotian Shelf (NSS). Spring phytoplankton bloom (SPB) of GoM: 114, SPB of NSS: 91; fall phytoplankton bloom (FPB) of GoM: 282, FPB of NSS: 289 (note that $y$-axis ranges differ between SPB and FPB timing anomalies)

sured water samples and SeaWiFS-derived chlorophyll concentrations in the GoM $(r=0.524, \mathrm{p}<0.01$, not shown). The modeled mean timing and magnitude of blooms also showed a good agreement with that of SeaWiFS (Fig. 6c,d).

A more detailed comparison of the annual bloom peak timing shows that the model successfully reproduced most of the regional and interannual variability in SPB timing in the GoM and NSS (Fig. 7a,b). The model also captured the difference of FPB timing between 2 sites (earlier in the GoM than NSS), but had more difficulty in capturing the FPB timing within each site (Fig. $7 \mathrm{c}, \mathrm{d}$ ). This is largely due to the uncertainties involved in identifying relatively weak and noisy FPB peak timing signals (compared to SPBs) from the SeaWiFS time series using a shifted Gaussian fit.

\section{Interannual variability of phytoplankton bloom timing and magnitude}

The model results show that the peak timing of SPB occurs typically around 24 April (Day 114) with a range of \pm 3 wk in the GoM and around 1 April (Day 91) with a range of \pm 2 wk in the NSS (Fig. 8a,b). The peak timing of FPB typically occurs around 9 October (Day 282) in the GoM and around 16 October (Day 289) in the NSS, and the variability in peak timing is somewhat less than for the SPB (Fig. 8c,d). Late FPBs in the NSS generally occur in the years after 1998. The GoM, in contrast, shows a less coherent decadal-scale trend in FPB timing.
The bloom magnitude analysis shows that the mean chlorophyll of SPB in the GoM has much larger variations than that on the NSS (Fig. 9a,b). For the FPB, the variations are smaller, relative to the SPB, but no apparent regional difference exists between GoM and NSS (Fig. 9c,d). Additionally, the springtime mean chlorophyll concentration is much higher than that in fall at both sites (Fig. 9).

\section{Factors influencing bloom timing and magnitude}

The SSS during the winter-spring period has proved to be correlated to the water column stability in the NSS-GoM region (Ji et al. 2007, Taylor \& Mountain 2009). Our model results also suggest a consistent pattern between the interannual variability of the winter-spring SSS anomaly and the peak timing of SPB in the GoM (Fig. 10a; $r=0.548, p<0.01$ ). In the NSS region, the winter-spring SSS anomaly also appears to exert control on the peak timing of SPB in many years (Fig. 10b, although the correlation is not highly significant $(\mathrm{r}=0.340, \mathrm{p}=0.104)$. However, the 0-50 m salinity difference (Fig. 10) is significantly correlated with SPB timing in both the GoM $(\mathrm{r}=0.750, \mathrm{p}<$ $0.01)$ and the NSS regions $(r=0.621, p<0.01)$. A larger mean 0-50 m salinity difference on the NSS (0.53) relative to the GoM (0.11) also explains the generally earlier SPB on the NSS despite its higher latitude. There were no significant relationships between SST or mean wind speed anomalies and SPB timing for either the GoM or NSS. 

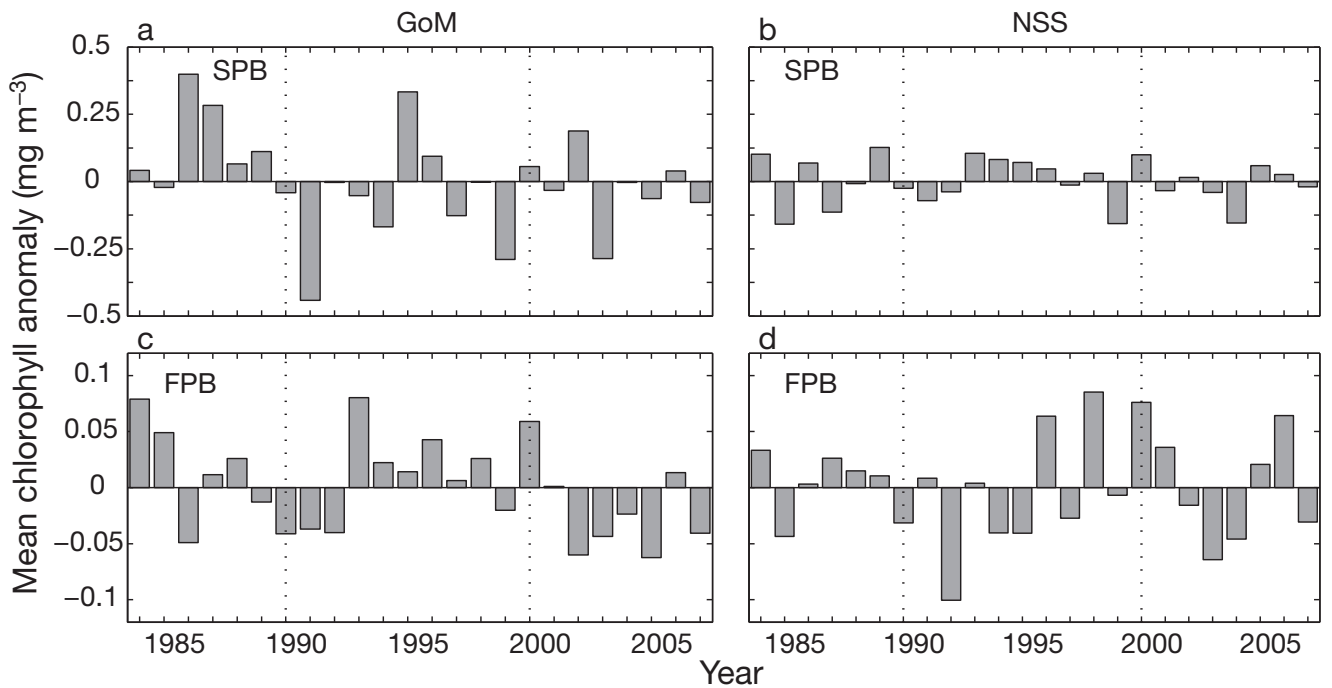

Fig. 9. Modeled interannual variability of mean chlorophyll concentration $\left(\mathrm{mg} \mathrm{m}^{-3}\right)$ during phytoplankton blooms in the (a,c) Gulf of Maine (GoM) and (b,d) Nova Scotian Shelf (NSS). Spring phytoplankton bloom (SPB) of GoM: 1.40, SPB of NSS: 1.28; fall phytoplankton bloom (FPB) of GoM: 0.80, FPB of NSS, 0.81

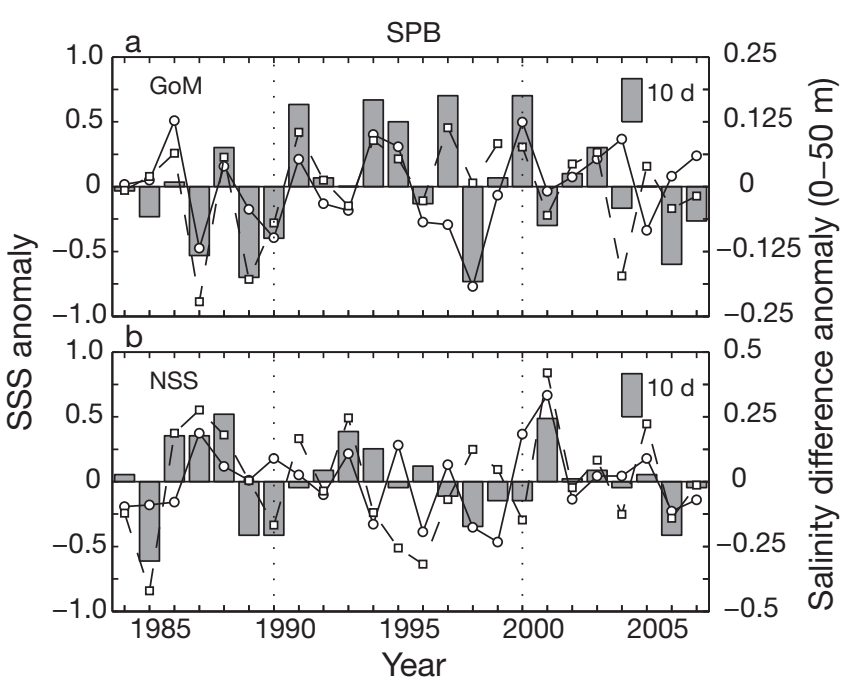

Fig. 10. Interannual variability of the anomaly of sea surface salinity (SSS, solid) and salinity differences (0 to $50 \mathrm{~m}$, dashed lines) and their relationships to the spring phytoplankton bloom (SPB) peak timing (bars) in the model. Mean salinity data from March to April were used to compute the anomaly. GoM: Gulf of Maine; NSS: Nova Scotian Shelf

Variations in FPB timing were more subtle than those for the SPB, and the dominant drivers were more difficult to identify. Stronger salinity-induced stratification in the fall on the NSS, where the $0-50 \mathrm{~m}$ SSS difference (mean in October and November) averaged 1.32, is responsible for the delayed modeled FPB relative to the GoM (where the mean $0-50 \mathrm{~m}$ salinity difference was 0.32 ). The correlation between the $0-50 \mathrm{~m}$ SSS difference and interannual changes

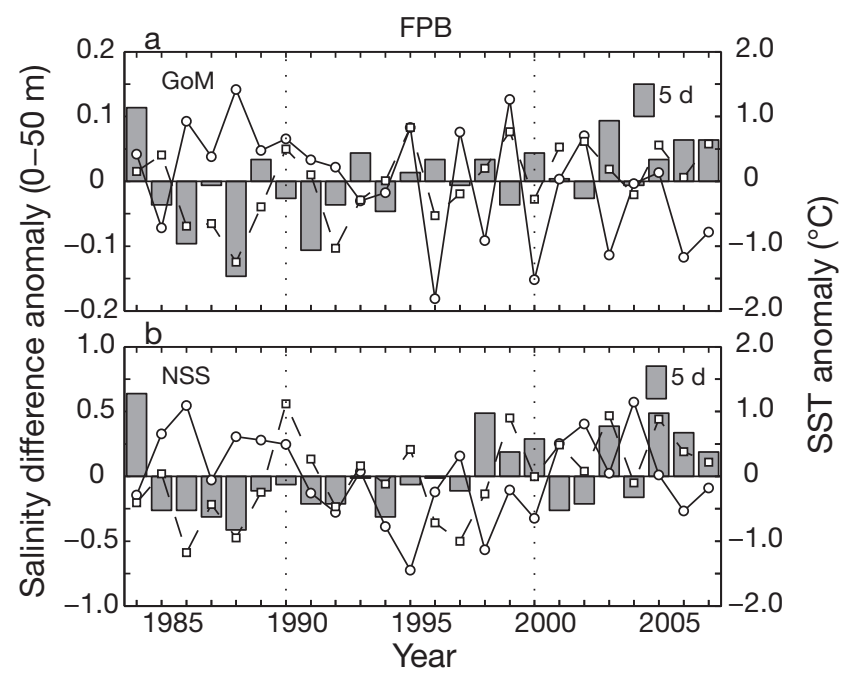

Fig. 11. Interannual variability of the anomaly of salinity differences (0 to $50 \mathrm{~m}$, solid lines) and sea surface temperature (SST, dashed lines) and their relationships to the fall phytoplankton bloom (FPB) peak timing (bars) in the model. Mean salinity data from October to November and mean SST in October were used to compute the anomaly. GoM: Gulf of Maine; NSS: Nova Scotian Shelf

in FPB timing were significant, but stronger stratification tended to delay the bloom rather than make it occur earlier (GoM: $r=-0.575, \mathrm{p}<0.01$; NSS: $r=-0.427$, $p<0.05)$. The SST also appears to impact the FPB peak timing, especially for the years since 1998 on the NSS (Fig. 11, where the general delay of FPBs matches the elevated October mean SST). A weak negative correlation between FPB timing and mean October/November wind speed was also found for 

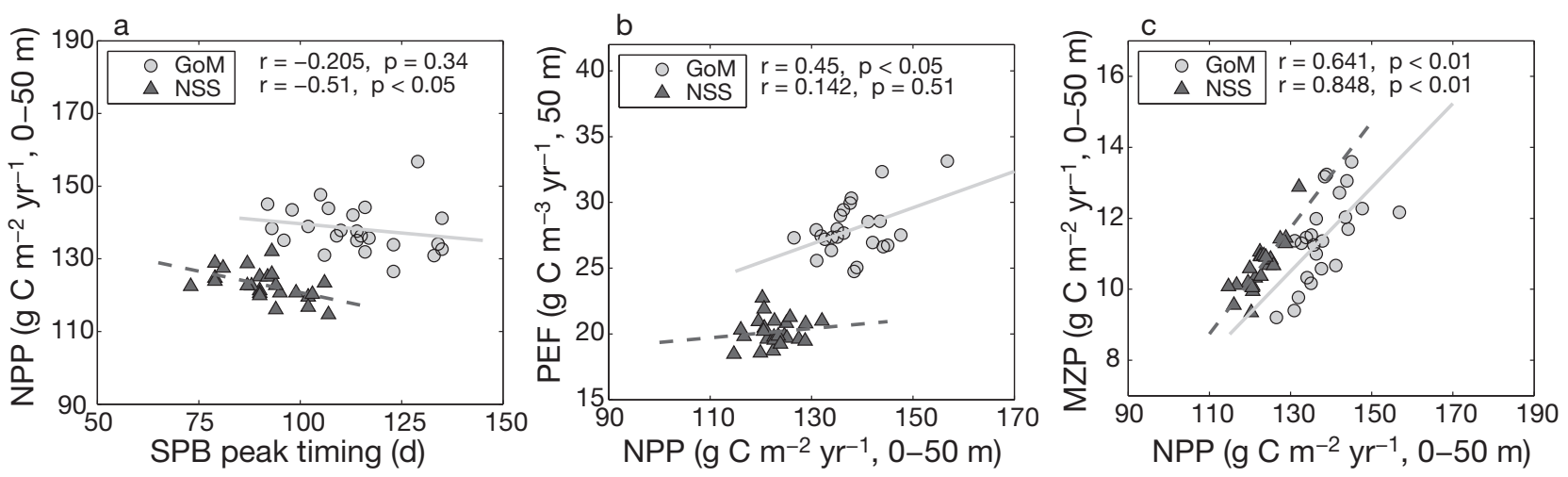

Fig. 12. Correlation among the (a) spring phytoplankton bloom (SPB) peak timing, (b,c) annual net primary production (NPP), (b) annual particle export flux (PEF), and (c) annual mesozooplankton production (MZP). GoM: Gulf of Maine; NSS: Nova Scotian Shelf

Fig. 13. Correlation between spring phytoplankton bloom (SPB) peak timing and (a) annual particle export ratio (pe-ratio) and (b) ratio of mesozooplankton production to primary production (z-ratio; $\mathrm{n}=24,1984$ to 2007 ). GoM: Gulf of Maine; NSS: Nova Scotian Shelf
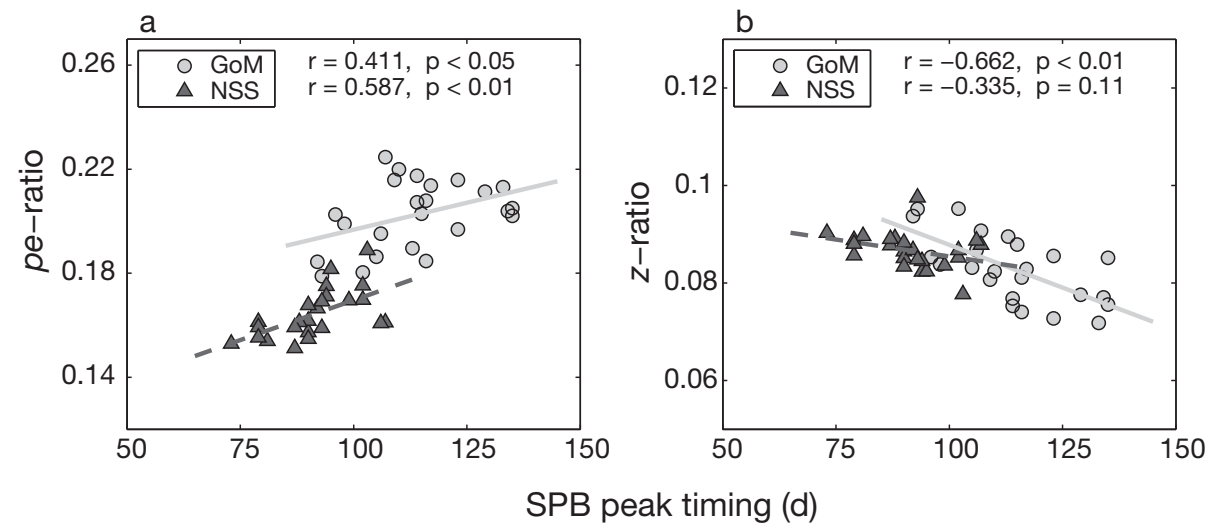

both the GoM (r = -0.45, p = 0.026) and NSS $(r=$ $-0.39, \mathrm{p}=0.057$ ).

All of the 5 environmental factors (SST, SSS, 0-50 m salinity difference, wind speed, and nutrients) were tested for their impacts on bloom magnitude, and the results suggest no significant correlation between them in both GoM and NSS. This result may in part be related to the bulk nature of the bloom magnitude definition (i.e. 4 mo average chlorophyll concentration), and more details are discussed in 'Discussion'.

\section{Relationship between bloom properties and annual productivity and export}

The model-computed total annual NPP in the euphotic zone averages $138 \pm 6.5 \mathrm{~g} \mathrm{C} \mathrm{m}^{-2} \mathrm{yr}^{-1}$ (mean \pm $\mathrm{SD}$ ) in the GoM and $123 \pm 6.5 \mathrm{~g} \mathrm{C} \mathrm{m}^{-2} \mathrm{yr}^{-1}$ on the NSS. These NPPs are somewhat lower than estimations from some previous studies in this region (e.g. O'Reilly et al. 1987, Townsend 1991, Mousseau et al. 1998), though consistent with others (Mills \& Fournier 1979). While variations in total annual primary productivity are modest, there is a weak negative correlation between annual primary production and SPB peak timing, especially on the NSS (Fig. 12a). The correlation between the annual PEF (GoM: $28.0 \pm 2.0 \mathrm{~g} \mathrm{C} \mathrm{m}^{-2} \mathrm{yr}^{-1}$; NSS: $20.2 \pm 1.0 \mathrm{~g} \mathrm{C} \mathrm{m}^{-2} \mathrm{yr}^{-1}$; mean $\pm \mathrm{SD}$ ) and NPP is only weakly positive, especially in the GoM (Fig. 12b). However, mesozooplankton production (GoM: $11.5 \pm$ $1.2 \mathrm{~g} \mathrm{C} \mathrm{m}^{-2} \mathrm{yr}^{-1}$; NSS: $10.6 \pm 0.7 \mathrm{~g} \mathrm{C} \mathrm{m}^{-2} \mathrm{yr}^{-1}$ ) exhibits a strong positive correlation with NPP in both the GoM and the NSS (Fig. 12c). The model-computed annual pe-ratio is around 0.20 in the GoM and 0.16 on the NSS, which falls within the range of previous estimations in the NSS-GoM region (e.g. $f$-ratio in Townsend 1998, Bisagni 2003). The pe-ratio has a significant positive correlation with SPB peak timing (Fig. 13a) in both the GoM and the NSS. The z-ratio, on the other hand, has a significant negative correlation with SPB peak timing (Fig. 13b). This pattern suggests that earlier spring blooms can enhance the transition from primary production to mesozooplankton production.

Fig. 14 compares the seasonal cycles of chlorophyll concentration, NPP, mesozooplankton productivity, and PEF for years with early SPBs and late FPBs (both cases are the mean of 5 yr with these characteristics) in the GoM and NSS. The chlorophyll in the 

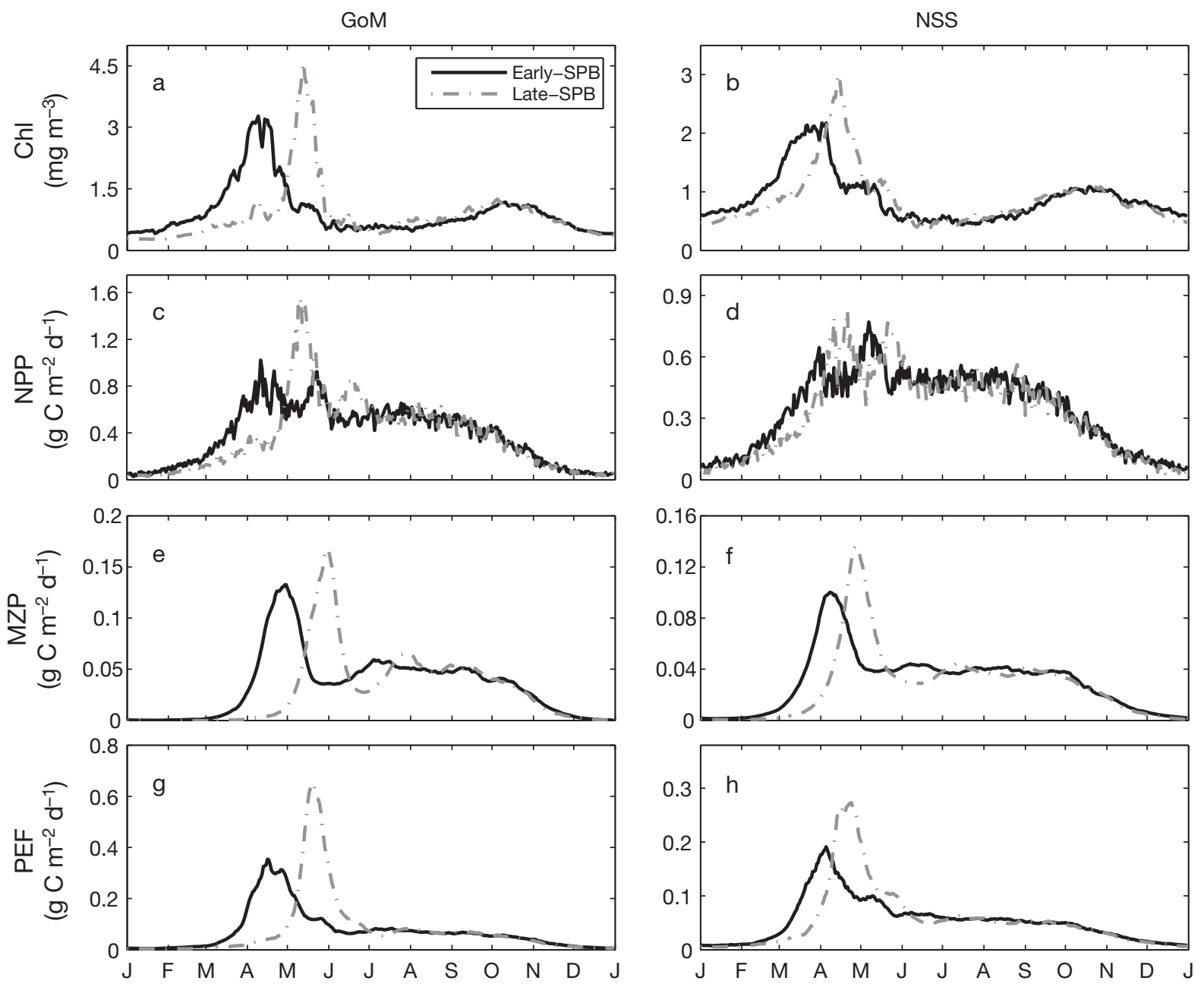

Time

Fig. 14. Comparison of the seasonal cycles of chlorophyll (chl, $0 \mathrm{~m}$ ), net primary production (NPP, 0 to $50 \mathrm{~m}$ ), mesozooplankton production (MZP, 0 to $50 \mathrm{~m}$ ), and particle export flux (PEF, $50 \mathrm{~m}$ ) between the early spring phytoplankton bloom (SPB) case and the late SPB case in the Gulf of Maine (GoM) and Nova Scotian Shelf (NSS). Data were averaged from 5 yr with both early (late) SPBs and late (early) fall phytoplankton blooms (FPBs)

years with early SPBs has a broader period with elevated concentrations, while the late SPB years have higher chlorophyll concentrations during the SPB peak (Fig. 14a,b). NPP in early SPB years has a lower peak value (especially in the GoM; Fig. 14c,d) but a slightly higher total annual value than in late SPB years (GoM: 139.5 versus $134.5 \mathrm{~g} \mathrm{C} \mathrm{m}^{-2} \mathrm{yr}^{-1}$; NSS: 125.5 versus $\left.119.2 \mathrm{~g} \mathrm{C} \mathrm{m}^{-2} \mathrm{yr}^{-1}\right)$. Mesozooplankton production lags behind NPP changes, but exhibits similar seasonal patterns and differences between early SPB and late SPB years. As was the case for NPP, early SPB years have slightly higher total annual mesozooplankton production values than late SPB years (GoM: 12.4 versus $10.6 \mathrm{~g} \mathrm{C} \mathrm{m}^{-2} \mathrm{yr}^{-1}$; NSS: 11.0 versus $\left.10.1 \mathrm{~g} \mathrm{C} \mathrm{m}^{-2} \mathrm{yr}^{-1}\right)$. However, the annual PEF in early SPB years is slightly lower than in the late SPB years (GoM: 26.4 versus $27.5 \mathrm{~g} \mathrm{C} \mathrm{m}^{-2} \mathrm{yr}^{-1}$; NSS: 19.5 versus $20.3 \mathrm{~g} \mathrm{C} \mathrm{m}^{-2} \mathrm{yr}^{-1}$ ).

It is notable that the FPB in the model does not exhibit a pronounced peak in productivity to match the peak in chlorophyll (Fig. 14a,b) and in response to increasing nutrients (Fig. 5). Surface productivity and biomass of large phytoplankton is elevated during the FPB relative to the summer minimum (not shown). A large part of the modeled chlorophyll peak during the FPB, however, reflects increasing phytoplankton chlorophyll-to-carbon ratios. Modeled chlorophyll-tocarbon ratios increase from surface values of $\sim 1: 75$ during the summer months to $\sim 1: 20$ during the winter. This response is consistent with observed ranges (Cloern et al. 1995). It arises from the Geider et al. (1997) dynamic chlorophyll-to-carbon formulation due to the 
stimulation of chlorophyll production in response to decreasing light and the alleviation of strong summer nutrient limitation.

\section{DISCUSSION}

Variations in water column stratification driven by interannual differences in salinity were significantly linked to variations in SPB and FPB timing in both the GoM and NSS. Less saline surface waters and sharper salinity gradients in the top $50 \mathrm{~m}$ led to earlier SPBs and delayed FPBs. The role of salinity in determining bloom timing in the simulations herein is consistent with previous results (e.g. Ji et al. 2007, 2009, Taylor \& Mountain 2009). It is notable, however, that variability in salinity-driven stratification explains only a moderate amount of the variability in bloom timing (particularly for the FPB). Other factors that may account for the unexplained variability include interannual variations in the weather. For example, Townsend et al. $(1992,1994)$ attributed interannual variation in the timing of spring bloom initiation to the occurrence of periods of weak or absent wind-driven mixing and high irradiance. However, our results showed no significant correlation between the wind speed and SPB timing and only a weak relationship between the mean October wind speed and FPB timing. More detailed analysis of the impact of weather variability on bloom timing is left to future work.

The peak timings of the SPB and FPB vary by over $30 \mathrm{~d}$ in both the GoM and NSS. Changes in bloom timing of this magnitude can have profound impacts on the recruitment of commercially important fish species in the NSS-GoM region (e.g. Platt et al. 2003, Friedland et al. 2008). The correlation in SPB timing between subsequent years was very small $(r=-0.176$ for the GoM, r $=0.083$ for the NSS), suggesting limited coherence of changes in bloom timing over multi-year time scales. Multi-year trends were more apparent for the FPB on the NSS, where the FPB tends to occur later in the years after 1998. This occurred in the simulations due to a combination of freshening and warming of surface waters (although the simplification of the 1D modeling approach might lead to uncertainly in capturing the possible covariation between SST and SSS in the model). While the model simulations recreated the approximate observed mean timing and magnitude of the FPB peak (i.e. Figs. 6 \& 7), interannual variations in FPB timing were more difficult to capture (Fig. 7), and SeaWiFS observations only extend back to 1998. The existence of a decadal-scale shift toward later FPB peaks on the NSS is thus uncertain.

Variability in salinity-driven stratification was not significantly related to changes in bloom magnitude.
However, this appears to be related in part to the bulk nature of the bloom magnitude definition (4 mo average chlorophyll). Comparison of the chlorophyll time series for an early SPB year versus a late SPB year indicates 2 distinct patterns. Early blooms are characterized by broader periods of elevated chlorophyll with moderate peak values, while late blooms have shorter periods of elevated chlorophyll with higher peaks (Fig. 14). Several mechanisms in the model contribute to these patterns. Early SPBs occur in water that is cold relative to late SPBs. Biological rates are relatively slow in cold water (all biological rates in the model used herein decrease by $50 \%$ with temperature decreasing by $10^{\circ} \mathrm{C}$, temperature coefficient $Q_{10}=2$ ) and both phytoplankton production and the zooplankton response associated with SPBs evolve over longer time scales than in warm waters. This extends the period of elevated chlorophyll during early SPBs. Two factors contribute to the higher peak chlorophyll during later SPBs. Nutrient concentrations increase monotonically and zooplankton concentrations decrease monotonically during the unproductive winter period lying between the FPB and the SPB. Later SPBs thus tend to start with higher nutrients and lower initial zooplankton concentrations that favor larger bloom peaks. Therefore, it is likely that the bloom magnitude and production are affected by multiple non-linearly interacting factors, and it is difficult to identify one single responsible environmental factor.

Numerous studies have postulated and, to varying extents, supported a general relationship between annual primary production and fisheries production (Ryther 1969, Iverson 1990, Ware \& Thompson 2005). However, interannual variations in primary production in the GoM and NSS were relatively modest in this study. The standard deviation in primary production was $3.4 \%$ and $4.7 \%$ of the mean primary production for the GoM and the NSS, respectively. If one assumes a linear relationship between fisheries production and primary production (sensu Iverson 1990), this could cause variations in fisheries productivity of similar scale. However, if fisheries productions reflect and integrate over several years of productivity fluctuations due to the multi-year life cycle of fish, this variation should be reduced. Regardless, results indicate that variations in fisheries productivity are likely secondary to the profound changes in recruitment that can occur due to changes in bloom timing.

Variations in annual primary productivity were only weakly related to SPB timing (Fig. 12). This result, and the generally modest variation in annual primary production, reflects the role of stratification in modulating the relative importance of light and nutrient limitation (e.g. Gargett 1997, Dutkiewicz et al. 2001, Sarmiento et al. 2004). Years with early SPBs are characterized by 
stronger stratification in the upper $50 \mathrm{~m}$ that alleviates light limitation and increases nutrient limitation by limiting vertical mixing. Winter conditions (i.e. deep mixing and the resulting strong light limitation of phytoplankton) persist for a shorter period, but less nutrients fuel production during the spring, summer, and fall. Less stratification in years with late SPBs alleviates nutrient limitation in the spring, summer, and fall, but increases light limitation. Both the GoM and NSS exhibit a slight negative trend with bloom timing (Fig. 12), suggesting that the net effect of alleviating light limitation is positive (as is typical for a high-latitude system). However, the significance of this relationship is marginal in both systems and is consistent with the GoM and NSS lying in a transition zone between predominant nutrient limitation (low latitude, non-upwelling systems) and light limitation (prevalent at high latitudes).

Mesozooplankton production scales in roughly direct proportion to primary production and z-ratios between $\sim 0.07$ and 0.10 are maintained in both systems. These values are typical for highly productive shelf ecosystems (Stock \& Dunne 2010), and interannual variations in primary productivity on the GoM and NSS do not drive large changes in this ratio. Variability in particle export, in contrast, was less strongly linked to variations in primary production, particularly on the NSS. Years with low annual primary productivity generally have later SPBs (Fig. 12) that have larger maximum chlorophyll (and higher peak phytoplankton biomass) during the SPB (Fig. 14, for underlying mechanisms refer to discussion in preceding paragraphs). Phytoplankton aggregation in the model used herein is modeled as a quadratic relationship with phytoplankton biomass (sensu Doney et al. 1996), and SPBs with higher peak phytoplankton biomass thus tend to have larger exports driven by aggregation (and high peratios, as shown in Fig. 13).

The analysis of interannual variations in bloom patterns and ecosystem productivity presented herein is subject to several limitations of the methodology that should be addressed in future work. The sources of forcing variability considered are limited to salinity (Supplement 3 at www.int-res.com/articles/suppl/ m426p105_supp.pdf) and local meteorological forcing. Other sources, such as changes in the nutrient characteristics of the slope water that fills the deep basins of the GoM, may also affect productivity and bloom patterns (Drinkwater et al. 2003, Townsend et al. 2006). The 1D modeling framework utilized herein does not account for lateral variations in temperature, nutrients, and other biological variables that may lead to the net advection of physical and biological properties between regions that appear locally as sources and sinks (e.g. Umoh \& Thompson 1994, Petrie \& Yeats
2000, Zakardjian et al. 2003). Lastly, the 1D framework accounts for the introduction of nutrients to well-lit surface waters via winter convective overturning and vertical mixing throughout the year, but neglects other sources such as coastal and estuarine upwelling (e.g. Townsend 1991). The omission of such processes may contribute to the somewhat low annual primary productivity estimates generated by the model, which are perhaps more representative of conditions over the deep basins of the GoM than those in near-coastal regions where the neglected processes may play a prominent role. The impact of upwelling, lateral advection, and deep nutrient sources on interannual variability in bloom dynamics and ecosystem productivity will be explored in future work using 3D circulation models. However, the effects of these processes will occur atop the seasonal-scale vertical mixing and convective dynamics whose roles have been elucidated herein and are fundamental to ecosystem dynamics in temperate and high-latitude ecosystems.

\section{SUMMARY}

A 1D ecosystem model was applied to capture the interannual variability of the phytoplankton bloom and production in the NSS and the GoM region over the period of 1984 to 2007. The model results showed that freshening can cause early SPBs and late FPBs; warming and weak wind has no effect on SPB timing but could delay FPBs. The modeled variation in annual primary productivity, mesozooplankton productivity, and PEF was modest. The variability of water column stability (and resultant timing of SPBs), appears to have only a weak impact on annual primary productivity, suggesting that the variations in annual productivity in the GoM and NSS reflect a combination of mutually negating factors: light limitation versus nutrient limitation (strong stratification alleviates light limitation at the surface but impedes nutrient supply from the bottom). Our model results imply that profound shifts in fisheries recruitment and production in the GoM and NSS region are more likely linked to changes in bloom timing rather than in annual productivity.

Acknowledgements. This study was supported by National Science Foundation grants OCE-0727033 and 0815838 provided to R.J., National Key Basic Research Program of China (973 Program) grant 2010CB428703 provided to Z.W., and a China Scholarship Council (CSC) government-sponsored graduate scholarship provided to H.S. This work was partially supported by the Shanghai Ocean University Program for International Cooperation (A-2302-10-0003), and the Leading Academic Discipline Project of Shanghai Municipal Education Commission (J50702). NCEP Reanalysis data were provided by the NOAA/OAR/ESRL PSD, Boulder, Colorado, USA, from their website at www.cdc.noaa.gov/. 


\section{LITERATURE CITED}

Baker KS, Frouin R (1987) Relation between photosynthetically available radiation and total insolation at the ocean surface under clear skies. Limnol Oceanogr 32:1370-1377

Bigelow HB (1926) Plankton of the offshore waters of the Gulf of Maine. Bull U S Bur Fish 40:1-509

Bigelow HB, Lillick LC, Sears M (1940) Phytoplankton and planktonic protozoa of the offshore waters of the Gulf of Maine. Part 1: numerical distribution. Trans Am Philos Soc 31:149-191

Bisagni JJ (2003) Seasonal variability of nitrate supply and potential new production in the Gulf of Maine and Georges Bank regions. J Geophys Res Oceans 108:8015 doi:10.1029/2001JC001136

> Cloern JE, Grenz C, Vidergar-Lucas L (1995) An empirical model of the phytoplankton chlorophyll:carbon ratio-the conversion factor between productivity and growth rate. Limnol Oceanogr 40:1313-1321

Cushing DH (1959) The seasonal variation in oceanic production as a problem in population dynamics. J Cons Int Explor Mer 24:455-464

Doney SC, Glover DM, Najjar RJ (1996) A new coupled, onedimensional biological-physical model for the upper ocean: applications to the JGOFS Bermuda Atlantic Timeseries Study (BATS) site. Deep-Sea Res II 43:591-624

Drinkwater KF, Petrie B, Smith PC (2003) Climate variability on the Scotian Shelf during the 1990s. ICES Mar Sci Symp 219:40-49

Durbin EG, Campbell RG, Casas MC, Ohman MD, Niehoff B, Runge J, Wagner M (2003) Interannual variation in phytoplankton blooms and zooplankton productivity and abundance in the Gulf of Maine during winter. Mar Ecol Prog Ser 254:81-100

Dutkiewicz S, Follows M, Marshall J, Gregg W (2001) Interannual variability in phytoplankton abundances in the North Atlantic. Deep-Sea Res II 48:2323-2344

Frank KT, Petrie B, Choi JS, Leggett WC (2005) Trophic cascades in a formerly cod-dominated ecosystem. Science 308:1621-1623

Friedland KD, Hare JA, Wood GB, Col LA and others (2008) Does the fall phytoplankton bloom control recruitment of Georges Bank haddock, Melanogrammus aeglefinus, through parental condition? Can J Fish Aquat Sci 65: 1076-1086

- Friehe CA, Schmitt KF (1976) Parameterization of air-sea interface fluxes of sensible heat and moisture by the bulk aerodynamic formulas. J Phys Oceanogr 6:801-809

Gargett AE (1997) The optimal stability 'window': a mechanism underlying decadal fluctuations in North Pacific salmon stocks. Fish Oceanogr 6:109-117

> Geider RJ, MacIntyre HL, Kana TM (1997) Dynamic model of phytoplankton growth and acclimation: responses of the balanced growth rate and the chlorophyll a:carbon ratio to light, nutrient-limitation and temperature. Mar Ecol Prog Ser 148:187-200

Greene $\mathrm{CH}$, Pershing AJ (2007) Climate drives sea change. Science 315:1084-1085

Iverson RL (1990) Control of marine fish production. Limnol Oceanogr 35:1593-1604

Ji R, Chen C, Franks PJS, Townsend DW and others (2006) Spring phytoplankton bloom and associated lower trophic level food web dynamics on Georges Bank: 1-D and 2-D model studies. Deep-Sea Res II 53:2656-2683

Ji R, Davis CS, Chen C, Townsend DW, Mountain DG, Beardsley RC (2007) Influence of ocean freshening on shelf phytoplankton dynamics. Geophys Res Lett 34:L24607 doi:10.1029/2007GL032010
Ji R, Davis CS, Chen C, Townsend DW, Mountain DG, Beardsley RC (2008) Modeling the influence of low-salinity water inflow on winter-spring phytoplankton dynamics in the Nova Scotian Shelf-Gulf of Maine region. J Plankton Res 30:1399-1416

Ji R, Davis CS, Chen C, Beardsley RC (2009) Life history traits and spatio-temporal distribution of copepods in the Gulf of Maine-Georges Bank region. Mar Ecol Prog Ser 384: 187-205

Kalnay E, Kanamitsu M, Kistler R, Collins W and others (1996) The NCEP/NCAR 40-year reanalysis project. Bull Am Meteorol Soc 77:437-471

Large WG, Pond S (1981) Open ocean momentum flux measurements in moderate to strong winds. J Phys Oceanogr 11:324-336

Lee HC, Rosati A, Spelman MJ (2006) Barotropic tidal mixing effects in a coupled climate model: oceanic conditions in the Northern Atlantic. Ocean Model 11:464-477

> Lorenzen CJ (1972) Extinction of light in the ocean by phytoplankton. ICES J Mar Sci 34:262-267

- Miller CB, Lynch DR, Carlotti F, Gentleman WC, Lewis CVW (1998) Coupling of an individual-based population dynamic model of Calanus finmarchicus to a circulation model for the Georges Bank region. Fish Oceanogr 7:219-234

Mills EL, Fournier RO (1979) Fish production and the marine ecosystems of the Scotian Shelf, eastern Canada. Mar Biol 54:101-108

> Mountain DG, Strout GA, Beardsley RC (1996) Surface heat flux in the Gulf of Maine. Deep-Sea Res II 43:1533-1546

> Mousseau L, Fortier L, Legendre L (1998) Annual production of fish larvae and their prey in relation to size-fractionated primary production (Scotian Shelf, NW Atlantic). ICES J Mar Sci 55:44-57

O'Reilly JE, Evans-Zetlin CE, Busch DA (1987) Primary production. In: Backus RH, Bourne DW (eds) Georges Bank. MIT Press, Cambridge, MA, p 220-233

> Petrie B, Yeats P (2000) Annual and interannual variability of nutrients and their estimated fluxes in the Scotian Shelf-Gulf of Maine region. Can J Fish Aquat Sci 57: $2536-2546$

Platt T, Fuentes-Yaco C, Frank KT (2003) Spring algal bloom and larval fish survival. Nature 423:398-399

> Platt T, White GN III, Zhai L, Sathyendranath S, Roy S (2009) The phenology of phytoplankton blooms: ecosystem indicators from remote sensing. Ecol Model 220:3057-3069

Ryther JH (1969) Photosynthesis and fish production in the sea. Science 166:72-76

Sameoto D (2001) Decadal changes in phytoplankton color index and selected calanoid copepods in continuous plankton recorder data from the Scotian Shelf. Can J Fish Aquat Sci 58:749-761

Sarmiento JL, Slater R, Barber R, Bopp L and others (2004) Response of ocean ecosystems to climate warming. Global Biogeochem Cycles 18:GB3003 doi:10.1029/2003 GB002134

Sherman K, Jaworski NA, Smayda TJ (1996) The Northeast Shelf ecosystem. Blackwell Scientific, Oxford

> Simpson JJ, Paulson CA (1979) Mid-ocean observations of atmospheric radiation. Q J R Meteorol Soc 105:487-502

> Song H, Ji R, Stock C, Wang Z (2010) Phenology of phytoplankton blooms in the Nova Scotian Shelf-Gulf of Maine region: remote sensing and modeling analysis. J Plankton Res 32:1485-1499

> Stock C, Dunne J (2010) Controls on the ratio of mesozooplankton production to primary production in marine ecosystems. Deep-Sea Res I 57:95-112

Sverdrup HU (1953) On conditions for the vernal blooming of phytoplankton. J Cons Int Explor Mer 18:287-295 
Taylor MH, Mountain DG (2009) The influence of surface layer salinity on wintertime convection in Wilkinson Basin, Gulf of Maine. Cont Shelf Res 29:433-444

Thomas AC, Townsend DW, Weatherbee R (2003) Satellitemeasured phytoplankton variability in the Gulf of Maine. Cont Shelf Res 23:971-989

Townsend DW (1991) Influences of oceanographic processes on the biological productivity of the Gulf of Maine. Rev Aquat Sci 5:211-230

Townsend DW (1998) Sources and cycling of nitrogen in the Gulf of Maine. J Mar Syst 16:283-295

Townsend DW, Spinard RW (1986) Early phytoplankton blooms in the Gulf of Maine. Cont Shelf Res 6:515-529

Townsend DW, Keller MD, Sierachi ME, Ackleson SG (1992) Spring phytoplankton blooms in the absence of vertical water column stratification. Nature 360:59-62

Townsend DW, Cammen LM, Holligan PM, Campbell DE, Pettigrew NR (1994) Causes and consequences of variability in the timing of spring phytoplankton blooms. DeepSea Res I 41:747-765

Townsend DW, Thomas AC, Mayer LM, Thomas M, Quinlan JA (2006) Oceanography of the Northwest Atlantic continental shelf. In: Robinson AR, Brink KH (eds) The sea, Vol

Editorial responsibility: Katherine Richardson,

Copenhagen, Denmark
14. Harvard University Press, Cambridge, MA, p 119-168

Umoh JU, Thompson KR (1994) Surface heat flux, horizontal advection, and the seasonal evolution of water temperature on the Scotian Shelf. J Geophys Res 99:20403-20416

Ware DM, Thompson RE (2005) Bottom-up ecosystem trophic dynamics determine fish production in the northeast. Pac Sci 308:1280-1284

Yamada K, Ishizaka J (2006) Estimation of interdecadal change of spring bloom timing, in the case of the Japan Sea. Geophys Res Lett 33:L02608 doi:10.1029/2005GL024792

Zakardjian BA, Sheng J, Runge JA, McLaren I, Plourde S, Thompson KR, Gratton Y (2003) Effects of temperature and circulation on the population dynamics of Calanus finmarchicus in the Gulf of St. Lawrence and Scotian Shelf: study with a coupled, three-dimensional hydrodynamic, stage-based life history model. J Geophys Res 108: $1-22$

Zhang Y, Rossow WB, Lacis AA, Oinas V, Mishchenko MI (2004) Calculation of radiative fluxes from the surface to top of atmosphere based on ISCCP and other global data sets: refinements of the radiative transfer model and the input data. J Geophys Res 109:D19105 doi:10.1029/2003 JD004457

Submitted: April 1, 2010; Accepted: December 16, 2010 Proofs received from author(s): March 7, 2011 